\title{
Factors Affecting the Disposition Effect in Tehran Stock Market
}

\author{
Reza Tehrani \\ Associate Professor, Management Department, University of Tehran, Tehran, Iran \\ Tel: 98-912-348-3888Ｅ-mail: rtehrani@ut.ac.ir \\ Niloofar Gharehkoolchian (Corresponding author) \\ MBA, University of Tehran \\ No. 27, Alley 56, Ghasrdasht Street, Shiraz 7115656969, Iran \\ Tel: 98-917-711-3420Ｅ-mail: Niloofar.gh995@gmail.com
}

Received: December 25, 2011

Accepted: January 18, 2012

Published: March 1, 2012

doi:10.5539/ibr.v5n3p40

URL: http://dx.doi.org/10.5539/ibr.v5n3p40

\begin{abstract}
Given the significance and perceived inevitability of disposition effect and its impact on investment decisions, we investigate factors affecting the disposition effect in the Tehran Stock Exchange. Four hypotheses were developed and the data used in the study were collected through availability sampling. One-sample t-test, two-sample t-test and one-way ANOVA were run to analyze the data while Pearson correlation test and multiple regressions were used to assess relationships among variables in question. The results of the analyses indicate that overconfidence and mental accounting were not significantly correlated with disposition effect. Regret aversion had a positive relationship with disposition effect while self control was negatively associated. It was also observed that there was a negative relationship between participants' level of education and their disposition effect indicating that the higher the level of education, the less the rate of disposition effect. Furthermore, the results of the study show that males enjoy a higher level of overconfidence than females, and 20 to 30 year-old age groups displayed much overconfidence than other age groups.
\end{abstract}

Keywords: Behavioral finance, Disposition effect, Overconfidence, Mental accounting, Regret aversion, Self control, Tehran stock exchange

\section{Introduction}

Recent research findings by a variety of researchers indicate that the impact of psychology on investors' decision-making cannot be ignored, and the mere reliance on Efficient Market Hypothesis (EMH), Capital Assets valuation model (CAPM), and the notion of "Homo economicus" to study these decisions may not be sufficient. The axiom that human beings act totally rationally when making economic decisions by taking into consideration all information available runs counter to some observations. In particular, when observing investors' behavior in the stock market, we come across behaviors which are inconsistent with those of an economic man. Hence, in recent years, scientists and researchers have increasingly paid attention to the science of behavioral finance, which by combining economics and psychology tries to account for investors' behaviors which are not often quite reasonable and formalizes biases affecting investment decisions taken by investors. Of these biases, one is "loss aversion" which, in practice, represents itself in the form of "disposition effect". Disposition effect accounts for investors' behaviors through an s-shaped value function.

Disposition effect forces investors to sell winner shares too early but hold loser shares in excess resulting in a decrease in the investors' gains. It also takes investors' portfolio away from their desired portfolio. In contrast, classical financial theories anticipate that an economic person would sell those loser shares with no expectation of a rise in their price, and, in turn, invest on those shares with a promising prospect and keep the winner shares as long as the company shows good performance. This requires making informed decisions to solve problems and uncertainties faced by investors. These problems may include economic factors such as less profitability, a rise in risk and the lack of balance in the desired portfolio.

Given the diametrically opposed explanations of rational decision making and observed disposition effect, empirical research on predicting investors' behavior in order to determine possible influential variables has attracted increasing 
attention. Scientists in the field of behavioral finance have demonstrated that individuals' personalities and their psychological dimensions may influence the economic decisions taken by them. These psychological dimensions are embodied in the form of a set of biases that control investors' behavior, the most noticeable of which are overconfidence, mental accounting, regret aversion, and self control. In this research, we contribute to the body of literature in behavioral finance by reporting the results of an empirical study conducted at the Tehran Stock Exchange to see if there is a possible relationship among these biases, and if so, what the nature of the relationship is.

\section{Theoretical Framework of the Study and a Review of Previous Empirical Studies}

Disposition effect was first introduced by Shefrin and Statman (1985) to describe the dominant tendency of investors to keep loser stocks for a long term but to sell winner stocks too early. They employed a model to explain why investors tend to sell winner stocks too early and to hold loser stocks for a long time. Investors may expect that the prices will return, sooner or later, to their previous status, that is to say, existing loser stocks may change into winner stocks and vice versa. To decide to keep the stocks or to sell them, investors can examine the value function. This implies that risk aversion concerns profit. In other words, investors are willing to identify profit. As a result, they sell profitable stock quickly. Barber and Odean (2002) use prospect theory to explain disposition effect (Glick, 1957). They believe that investors typically consider the purchase price as a reference point, upon which they decide whether to keep their stocks or to sell them. For instance, if they expect that the price of certain stocks is going to rise they will buy it and make the price as a reference point. Given the desirability of prospect theory, in the case that the stock prices increases the investor identify the profit through selling the stocks. If, on the other hand, the stocks are dropping off, the investor tries to convince himself that the price will raise and, therefore, he keeps the loser stocks. Odean (1998) has investigated disposition effect by analyzing the information related existing transaction accounts in a brokerage (Pempin, 2009). He found that stockholders, on the whole, prefer loser stocks over the winner stocks which are confirmed by other studies (Shefrin \& Statman, 1985; Odean, 1998; Weber \& Camerer, 1998; Locke \& Mann, 2000; Grinblatt \& Keloharju, 2001; Ranguelova, 2001) that come across similar findings.

The prevailing model for studying the disposition effect and the theoretical framework for this study is depicted in Figure 1. In the following section, we expand on each of the variables and present the hypotheses used for this study.

\subsection{Overconfidence}

Kahneman and Turesky (1982) suggested that people often misjudge how likely it is for an event to happen and they overestimate incidence possibility of the event than the actual number of incidence in reality (Odean, 1998). Pempin (2009) in a book titled "Behavioral finance and capital management" points out that overconfidence as a concept has been investigated in a wide range of psychological experiments and studies done on typology, suggesting that people overestimate their ability both in perdition and the accuracy of the information provided to them (Barber \& Odean, 2002). He also noted that individuals have a poor performance in estimating probabilities and the events they regard as inevitable are much less than 100 percent likely to happen. He states that people often consider themselves more intelligent than they are in actuality. WineStein (1980) and Kunda (1980) observed that people anticipate that good things happen more to themselves than to others. Vin Stein (1980) argues that people overrate their ability to do things very well than what actually they afford and this overrate increases when things are under their control (Weber \& Camerer, 1998). Odean (1998) suggested that overconfidence may arise due to overestimation of the accuracy of secret codes and investors' knowledge about securities (Pempin, 2009). Individuals always remember their successes, while easily forgetting their failures. On the other hand, stockholders are more likely to overrate the accuracy of their personal estimations about securities' value than estimations made by other people. Overconfidence often leads to taking wrong decisions. As a result, stockholders miss the chance of correcting their mistakes, so they cannot make a right decision. Consequently, reliance on overconfidence may result in wrong decisions by stockholders and, thus, influencing disposition effect. Based on this assumption, the first research hypothesis is formulated as follows:

\section{H1: There is a significant relationship between overconfidence and disposition effect.}

\subsection{Mental Accounting}

Dr. Richard Thaler (1980) first defined mental accounting as "people's tendency to encode, classify, and evaluate economic outcomes by ranking their scores in the form of a set of mental accounts" (Thaler, 1980). Mental accounting has been used to account for economical phenomena. Mental accounting as a bias plays an important role in decisions made about household budget (Thaler, 1985), transactions in stock exchanges (Shefrin \& Statman, 1985) and consumption life cycle (Shefrin \& Statman, 1985). Kahneman and Turesky (1981), Thaler (1985), Kahneman and Lovallo (1993) stated that stockholders divide all revenues into several small parts; each called a mental account while the whole process is called mental accounting. They treat each mental account differently. As a result, disposition effect may originate from mental accounting. Furthermore, mental accounting may lead investors to select a reference 
point for each stock in order to determine whether the stock under question is winner or loser. Therefore, the second hypothesis of the study is raised as:

\section{H2: There is a significant relationship between mental accounting and disposition effect.}

\subsection{Regret Aversion}

Shefrin and Statman (1985) have demonstrated that regret is an emotional state by which the effected individual imagines that if he had taken another decision in the past other than what he really took, he may have been got better results (Shefrin \& Statman, 1985) and this is another factor which may lead to disposition effect. Regret aversion is a vital factor which accounts for why it is difficult for investors to indentify profit and loss. Identification of loss is a signal of the investor's misjudgment. Shefrin and Statman (1985) also believe that a sense of regret resulting from loss is stronger than a feeling of pride due to gaining a profit. According to Thaler (1980) regret theory is a motivational decision making theory with the main assumption that people are concerned about the feeling they experience due to outcomes of the decisions they have made (Thaler, 1980). Since stockholders are responsible for their decisions, sometimes they feel regretful for their previous decisions. The desirability function is steeper for those stockholders who consider themselves responsible for their decisions. The marginal value of profit and loss decreases when the number of profits or losses increases meaning that the earlier profits or losses worth more than subsequent profits or losses. Therefore, stockholders tend to maintain loser stocks as they are less sensitive about the next losses. Similarly, they are more willing to sell winner stocks because they are not sensitive about subsequent earnings.

\section{H3: There is a significant relationship between regret aversion and disposition effect.}

\subsection{Self Control}

Self control, as the name suggests, means controlling the individuals' feelings. Investors who show a high level of self control avoid identification of their losses but are more willing to recognize their profits. However, to prevent much loss they are capable of indentifying them. According to Glick (1957) the investor's unwillingness to recognize losses leads to a self control problem (Grinblatt \& Keloharju, 2001). He states that in spite of principles of rationality, investors have a strong desire to maintain the loser stocks. Whenever profit is reachable, investors frequently say they and their colleagues send their stocks very quickly and gaining a profit they leave the market. "Little profits and high losses" is a phrase used by investors describing on of the problems they encounter in their business. To illustrate how disposition effect can be regarded as a self control problem, Thaler and Shefrin (1981) suggest that self control is an internal conflict between the rational part (planner or manager) and the primary, emotional, and short-sighted parts (subject or agent ) (Tversky \& Kahneman ,1981). Since the agent part has the power of influencing a person's actions, the planner part react to it by presenting determination or uses a commitment making instrument. In order to adapt agent-planner model with disposition effect analysis, the desirability of the agent will be regarded a function of conditions dominating different mental accounts. According to Thaler and Shefrin (1981), investors tend to maintain the loser stocks to postpone the feeling of regret, while they sell winner stocks very quickly in order to experience the sense of pride resulting from making the right choice as soon as possible. The planner (rational) part may not be so strong to prevent the agent part interfering in decision making process. Shefrin and Statman (1985) suggest that investors may employ different techniques of commitment or obligation predetermination to control they resistance against recognizing the loss (Shefrin and Statman 1985). For example, professional stockholders set aside a percentage of the initial purchase price of stocks for themselves (e.g. $10 \%$ of the purchase price) to sell the stocks when the resultant loss amounts to that percentage (e.g. $10 \%$ ). This is considered as a solid rule for stockholders never ever breaching it. Stop-loss orders are another instance of the techniques used by stockholders. These orders are applied to reduce the risk associated with loss but their main advantage is that they allow stockholders to recognize the losses in their favor at a predetermined point.

\section{H4: There is a significant relationship between self control and disposition effect.}

\section{Research Method and Findings}

The aim of the present study is to examine the relationships between four behavioral biases and disposition effect and to take some efforts to reduce these biases among stockholders in Tehran Stock Exchange. Regarding the aim of the study it is a practical research which uses a descriptive survey method.

The population under study included all actual stockholders in Tehran Stock exchange Hall among which 196 samples were selected through availability sampling method based on infinite population sampling formula. The instruments used for data collection was a questionnaire containing 34 items conceptualized clearly and intelligibly for all investors' groups involved in the stock exchange. However, two terms, winner stocks and loser stocks were explained in order to be assured of comprehensibility of the items. 
In order to measure reliability of the instrument, behavioral finance experts were consulted with their suggestions were applied to all items of the questionnaire if necessary. Besides, Cronbach Alpha was used to determine validity of the questionnaire which was measured as 0.868 .

After collecting the required data, mean and frequency of respondents' demographic factors were determined by descriptive statistics. In order to test research hypotheses, different statistical tests such as Pearson correlation analysis, sample t-test, two-sample t-test, one-way ANOVA, and multiple regression analysis were employed. In addition, to examine present situation regression analysis was run and a linear equation was presented for prediction. Table 1 summarizes Pearson correlation for the biases and disposition effect.

\subsection{Findings of the Study}

Rotated matrix using varimax rotation method was employed for exploratory factor analysis of the questionnaires as a method of identification and analysis of factors. The results showed four main factors influencing disposition effect which can explain $56.985 \%$ of the variance. The results for the factor analysis indicate that the existing data are appropriate for factor analysis and the instruments used in the study provide an accurate measurement of the variables under question.

Based on mean test of the population, the amount of disposition effect, t-value, is 7.726 which is higher than 1.96 , so it can be concluded that there is a high level of disposition effect in Tehran Stock Exchange. T-value for overconfidence is 7.398 which is greater than 1.96 and, thus, we can conclude that there is a high level of overconfidence in Tehran Stock Exchange. T-value for mental accounting is 12.288 which is greater than 1.96 and, as a result, it is concluded that there is a high level of mental accounting in Tehran Stock Exchange. The related t-value for regret aversion amounts to 10.258 which is higher than 1.96. Therefore, it can be concluded that a high level of regret aversion can be observed in Tehran Stock Exchange. Finally, t-value for self control is -7.006 which is much less than 1.96. So we come to conclusion that there is no self control in Tehran Stock Exchange.

Pearson correlation coefficient for overconfidence and disposition effect is equal to 0.050 at the level of significance of 0.050 which is higher than 0.05 . As a result, it can be said that there is no significant relationship between overconfidence and disposition effect in Tehran Stock Exchange.

The value of Pearson correlation coefficient for mental accounting and disposition effect is equal to 0.098 at the level of significance of 0.166 which is higher than 0.05 . As a result, there is no significant relationship between mental accounting and disposition effect in Tehran Stock Exchange.

The value of Pearson correlation coefficient for regret aversion and disposition effect is equal to 0.433 at the level of significance of 0.00 which is less than 0.05 . As a result, there is a significant relationship between regret aversion and disposition effect and since the value of the correlation coefficient is positive, then it can be said that this relationship is positive indicating that the more regret aversion, the more disposition effect.

The value of Pearson correlation coefficient for self control and disposition effect is equal to -0.702 at the level of significance of 0.00 which is less than 0.05 so there is a significant relationship between self control and disposition effect. Since the coefficient is negative, therefore, it can be concluded that this relationship is negative which means that an increase in the level of self control will result in a decrease in the level of disposition effect and visa versa. The following equation was obtained based on multiple regression analysis:

$$
\mathrm{Y}=3.099+\text { 0/230(RA) }- \text { 0/611(SC) }
$$

As a result, one unit of change in regret aversion will lead to 0.230 unit of change in disposition effect. In addition, a unit of change in self control will result in 0.611 unit of change in the opposite direction in disposition effect.

Furthermore, of moderating variables-gender, age, level of education and work experience in the Tehran Stock Exchange-only the level of education is significantly related to disposition effect. Level of significance in the results obtained for ANOVA is 0.032 which is less than 0.05 indicating that $\mathrm{H}_{0}$ is rejected, while $\mathrm{H}_{1}$ is confirmed. Besides, the results of Tukey test indicate that stockholders with a diploma degree or under diploma showed the highest level of disposition effect while those with a master degree or Ph.D demonstrated the lowest level of disposition effect. It should be mentioned that participants' level of has no relationship with other variables.

The results of two sample independent t-tests indicate that participants' gender has a significant relationship with disposition effect at level of significance of 0.003 which is much less than 0.05 , showing that $\mathrm{H}_{0}$ is rejected but $\mathrm{H}_{1}$ is confirmed. The mean score for females' self confidence is 2.9565 while that of males is 3.4096 . Therefore, it can be concluded that men are more confident than women. The test statistic is equal to -3.053.

The level of significance for the testing the relationship between age and overconfidence is 0.024 (i.e. less than 0.05). As a result $\mathrm{H}_{0}$ is rejected but $\mathrm{H}_{1}$ is confirmed. The results of Tukey test suggest that stockholders whose age is 20 to 30 
show the highest level of overconfidence, while those who are over 60 have the least amount of self confidence. However, other variables had no significant relationship with age.

The results of ANOVA test show that "disposition effect" and "experience" are not significantly related at level of significance of 0.192 and, thus, $\mathrm{H}_{0}$ is confirmed. The relationship between "mental accounting" and "regret aversion" is not also significant at level of significance of 0.800 and, as a result, $\mathrm{H}_{0}$ is confirmed. Finally, the relationship between "self control" and "experience" is not also significant at level of significance of 0.372 and, therefore, $\mathrm{H}_{0}$ is confirmed.

\section{Discussion and Conclusions}

Based on the findings of the study, in general, it can be concluded that biases have a considerable influence on decisions made by stockholders in Tehran Stock Exchange. Of the four hypotheses proposed in the study, two hypotheses were confirmed but the other two were rejected.

The results obtained for the first hypothesis indicate that there is a significant relationship between stockholders' overconfidence and their disposition effect in Tehran Stock Exchange.

The results of the second hypothesis suggest that there is a significant relationship between mental accounting and disposition effect in Tehran Stock Exchange.

Based on the statistical results obtained for the third hypothesis it was found that there is a significant relationship between regret aversion and disposition effect. Besides, this relationship is positive. Therefore, it is recommended that by holding different workshops and informing stockholders through mass media to raise their awareness about these biases and help them to control and reduce these biases as much as possible.

The results of the fourth hypothesis are indicative of the existence of a significant relationship between self control and disposition effect in Tehran Stock Exchange. But as the relationship is negative it is suggested that by training stockholders in using techniques associated with increasing their self control help them to improve the quality of decision making process.

In addition, the results of the study suggest that men and younger stockholders show more overconfidence than women and older stockholders. It was also that higher levels of education lead to a decrease in the level of disposition effect. Therefore, it is recommended that to increase investors' level of education by holding training classes and providing them with learning materials.

Finally, given the impotence of disposition effect for investors' transaction decisions, following topics are suggested for future research:

1. Conducting similar studies focusing on other psychological factors.

2. Conducting similar studies in other investment markets such as capital market transactions.

3. Investigating the effects of interaction among psychological factors considered in the present study i.e. overconfidence, mental accounting, regret aversion, and self control.

4. Conducting more research considering macro-level factors such as recession and boom and industrial environments.

\section{References}

Barber, B. M., \& Odean, T. (2002). Online investors: Do the slow die first?. The Review of Financial Studies Special, 15, 455-488. http://dx.doi.org/10.1093/rfs/15.2.455

Glick, B. (1957). Experimental modification of the growth of the Bursa of Fabricius. Poultry Science, 36, 18-23.

Grinblatt, M., \& Keloharju, M. (2001). What makes investors trade?. The Journal of Finance, 56, 589-616. http://dx.doi.org/10.1111/0022-1082.00338

Kahneman, D., \& Lovallo, D. (1993). Timid choices and bold forecasts: A cognitive perspective on risk taking. Management Science, 39, 17-31. http://dx.doi.org/10.1287/mnsc.39.1.17

Kahneman, D., \& Tversky, A. (1974). Judgment under uncertainty: Heuristics and biases. Science, 185, 1124-1131. http://dx.doi.org/10.1126/science.185.4157.1124

Kunda, Z. (1987). Motivated inference: Self-serving generation and evaluation of causal theories. Journal of Personality and Social Psychology, 53, 636-647. http://dx.doi.org/10.1037/0022-3514.53.4.636

Locke, P. R., \& Steven, C. M. (2000). Do Professional Traders Exhibit Loss Realization Aversion? Working Paper, Finance Department, School of Business and Public Management, The George Washington University, Washington D C.

Odean, T. (1998). Are investors reluctant to realize their losses?. The Journal of Finance, 53, 1775-1797. http://dx.doi.org/10.1111/0022-1082.00072 
Pempin, M. M. (2009) Behavioral Finance and Capital Management. (A. Badri, Trans.). Tehran: Keyhan Press. Ranguelova, E. (2001). Disposition Effect and Firm Size: New Evidence on Individual Investor Trading Activity. Center for Mathematics and Computer Science, Harvard University, Cambridge, MA.

Shefrin, H. (2007). Behavioral finance: biases, mean-variance returns, and risk premiums. CFA Institute Conference Proceedings Quarterly, 24 (2), 4-12. http://dx.doi.org/10.2469/cp.v24.n2.4700

Shefrin, H., \& Statman, M. (1985). The disposition to sell winner stocks too early and ride loser stocks too long: Theory and evidence. The Journal of Finance, 40, 777-790. http://dx.doi.org/10.2307/2327802

Thaler, R. H. (1980). Toward a positive theory of consumer choice. Journal of Economic Behavior and Organization, 1, 39-60. http://dx.doi.org/10.1016/0167-2681(80)90051-7

Thaler, R. H. (1985). Mental accounting and consumer choice. Marketing Science, 4, 199-214. http://dx.doi.org/10.1287/mksc.4.3.199

Thaler, R., \& Shefrin, H. (1981). An economic theory of self-control. Journal of Political Economy, 89, 392-410. http://dx.doi.org/10.1086/260971

Tversky, A., \& Kahneman, D. (1981). The framing of decisions and the psychology of choice. Science, 211, 454-455. http://dx.doi.org/10.1126/science.7455683

Weber, M., \& Camerer, C. F. (1998). The disposition effect in securities trading: An experimental analysis. Journal of Economic Behavior \& Organization, 33, 167-184. http://dx.doi.org/10.1016/S0167-2681(97)00089-9

Weinstein, N. (1980). Unrealistic optimism about future life events. Journal of Personality and Social Psychology, 39, 806-820. http://dx.doi.org/10.1037/0022-3514.39.5.806

Table 1. Pearson Correlation Matrix for the Biases and Disposition Effect

\begin{tabular}{|c|c|c|c|c|c|c|}
\hline \multicolumn{2}{|c|}{} & $\begin{array}{c}\text { Disposition } \\
\text { effect }\end{array}$ & $\begin{array}{c}\text { Overconfi } \\
\text { dence }\end{array}$ & $\begin{array}{c}\text { Mental } \\
\text { accounting }\end{array}$ & $\begin{array}{c}\text { Regret } \\
\text { aversion }\end{array}$ & Self control \\
\hline \multirow{4}{*}{ Disposition effect } & Pearson correlation & 1 & 0.050 & 0.098 & 0.433 & -0.702 \\
\cline { 2 - 7 } & Level of sig. & & 0.486 & 0.166 & .000 & .000 \\
\cline { 2 - 7 } & Total & 200 & 200 & 200 & 200 & 200 \\
\hline \multirow{4}{*}{ Overconfidence } & Pearson correlation & 0.050 & 1 & 0.157 & -0.108 & -0.002 \\
\cline { 2 - 7 } & Level of sig. & 0.486 & & 0.027 & 0.128 & 0.974 \\
\cline { 2 - 7 } & Total & 200 & 200 & 200 & 200 & 200 \\
\hline \multirow{3}{*}{ Regret aversion } & Pearson correlation & 0.098 & 0.157 & 1 & 0.076 & -0.044 \\
\cline { 2 - 7 } & Level of sig. & 0.166 & 0.027 & & 0.284 & 0.534 \\
\cline { 2 - 7 } & Total & 200 & 200 & 200 & 200 & 200 \\
\cline { 2 - 7 } & Pearson correlation & 0.433 & -0.108 & 0.076 & 1 & -0.326 \\
\hline \multirow{4}{*}{ Self control of sig. } & .000 & 0.128 & 0.284 & & .000 \\
\cline { 2 - 7 } & Total & 200 & 200 & 200 & 200 & 200 \\
\cline { 2 - 7 } & Pearson correlation & -0.702 & -0.002 & -0.044 & -0.326 & 1 \\
\cline { 2 - 7 } & Level of sig. & .000 & 0.974 & 0.534 & .000 & 200 \\
\hline
\end{tabular}

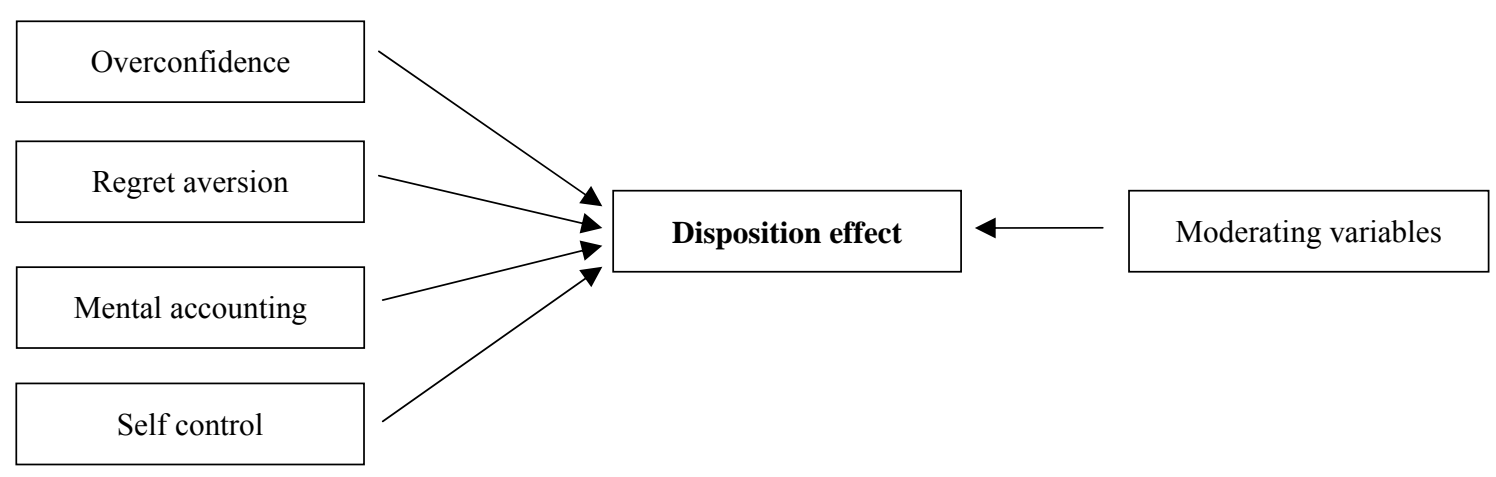

Figure 1. Theoretical Framework of the Study 